\title{
Behavioral and Neurobiological Consequences of Social Subjugation during Puberty in Golden Hamsters
}

\author{
Yvon Delville, Richard H. Melloni Jr, and Craig F. Ferris \\ Neuropsychiatric Sciences Program, Psychiatry Department, University of Massachusetts Medical Center, \\ Worcester, Massachusetts 01655
}

\begin{abstract}
In golden hamsters, offensive aggression is facilitated by vasopressin and inhibited by serotonin. We tested whether these neurotransmitter systems respond to modifications resulting from the stress of threat and attack (i.e., social subjugation) during puberty. Male golden hamsters were weaned at postnatal day 25 (P25), exposed daily to aggressive adults from P28 to $\mathrm{P} 42$, and tested for offensive aggression as young adults (P45). The results showed a context-dependent alteration in aggressive behavior. Subjugated animals were more likely to attack younger and weaker intruders than nonsubjugated controls. Conversely, subjugated animals were less likely to attack animals of similar size and age. After testing, the animals were killed, and their brains were collected to determine whether these behavioral changes are underlined by changes in the vasopressin and serotonin systems. Social subjugation resulted
\end{abstract}

In golden hamsters, aggressive behavior performed by resident males against intruders is controlled in part by the interaction of two neurotransmitter systems. The behavior is facilitated by arginine vasopressin (AVP) and inhibited by serotonin (5-HT) (Ferris and Potegal, 1988; Ferris et al., 1997). Microinjections of low doses of AVP (90 nM in $100 \mathrm{nl}$ of saline) within the anterior hypothalamus accelerate the onset and enhance the intensity of aggressive behavior toward intruders (Ferris et al., 1997). Conversely, microinjections of AVP receptor antagonist within the same area inhibit offensive aggression (Ferris and Potegal, 1988). Furthermore, another hypothalamic site, the ventrolateral hypothalamus, is also responsive to AVP in the control of offensive aggression (Delville et al., 1996). The effects of AVP on aggression are not limited to golden hamsters. In rats, aggressive behavior can also be facilitated by microinjections of AVP within the lateral septum and amygdala (Koolhaas et al., 1990, 1991). In prairie voles, AVP injections within the cerebral ventricles activates aggressive behavior (Winslow et al., 1993). In humans and rats, high indexes of aggressivity correlate with high levels of AVP in the CSF (Coccaro, 1996; Haller et al., 1996). Together, these data indicate that the AVP system is involved in the facilitation of aggressive behavior in several species of mammals.

Received Nov. 6, 1997; revised Jan. 5, 1998; accepted Jan. 8, 1998.

This work was supported by Grant MH52280 from the National Institute of Mental Health awarded to C.F.F. and by a Joseph P. Healy Endowment award to Y.D. We are grateful to Tom Knott, Karim Mansour, Mary-Alice Abbott, Tamima Posy, Rob McKenna, Phuong Xuang Hang, and J. C. Klick for expert technical support. We are also grateful to Dr. S. Leeman for helpful comments on this manuscript.

Correspondence should be addressed to Dr. Yvon Delville. Psychiatry Department, University of Massachusetts Medical Center, 55 Lake Avenue North, Worcester, MA 01655.

Copyright (C) 1998 Society for Neuroscience $0270-6474 / 98 / 182667-06 \$ 05.00 / 0$ in a $50 \%$ decrease in vasopressin levels within the anterior hypothalamus, a site involved in the regulation of aggression. Furthermore, whereas the density of vasopressinimmunoreactive fibers within the area was not significantly altered in subjugated animals, the number of serotoninimmunoreactive varicosities within the anterior hypothalamus and lateral septum was $20 \%$ higher in subjugated animals than in their controls. These results establish puberty as a developmental period sensitive to environmental stressors. Furthermore, the results show that changes in the vasopressin and serotonin systems can correlate with behavioral alterations, supporting the role of these two neurotransmitters in the regulation of aggression.

Key words: aggression; vasopressin; serotonin; hypothalamus; development; adolescence

In contrast, the 5-HT system is associated with the inhibition of aggressivity in various species (Olivier and Mos, 1990; Coccaro, 1996; Kraemer and Clarke, 1996). In golden hamsters, peripheral treatment with fluoxetine, a 5-HT reuptake inhibitor, blocks the effects of AVP microinjections within the anterior or ventrolateral hypothalamus, although having no effect on nonagonistic behaviors (Delville et al., 1995; Ferris et al., 1997). Furthermore, peripheral fluoxetine treatment inhibits AVP release within the anterior hypothalamus (Ferris, 1996). Therefore, it is possible that the effects of peripheral fluoxetine treatment reflect an interaction between 5-HT terminals and AVP neurons as well as AVP-sensitive neurons. This possibility is supported by the presence of 5-HT terminals on hypothalamic AVP neurons in golden hamsters (Ferris et al., 1997). Moreover, as the effects of 5-HT are presumed to involve $5-\mathrm{HT}_{1 \mathrm{~A} / \mathrm{B}}$ receptors (Sijbesma et al., 1990, 1991; Joppa et al., 1997), these colocalize with AVP receptors within the hypothalamus (Delville et al., 1995; Ferris et al., 1997), (C. F. Ferris, unpublished results).

Aggressive behavior in several species, including golden hamsters, can also be modulated by environmental factors such as stress resulting from social subjugation (Potegal et al., 1993; Blanchard et al., 1995). In these cases, subjugated animals are more submissive and less aggressive during subsequent testing against conspecifics of similar size and age. However, it is possible that the behavior of socially subjugated individuals is contextdependent; i.e., enhanced aggression toward weaker targets and decreased aggression toward more challenging targets. The goals of the following experiments were twofold. The first goal was to test the effects of social subjugation on subsequent agonistic behavior under different contexts. The second goal was to correlate changes in agonistic behavior with changes in the AVP and 
5-HT systems. Furthermore, in this study, experimental animals were socially subjugated during puberty because of the importance of this developmental period in the establishment of social relationships (Sachser, 1993).

\section{MATERIALS AND METHODS}

Animals and treatment. Adult male and female golden hamsters $(n=20)$ were purchased from Harlan Sprague Dawley (Indianapolis, IN). The females were mated, became pregnant, and gave birth $16 \mathrm{~d}$ later. Male pups were weaned and single-housed on postnatal day 25 (P25). On P27-P28, all animals were prescreened to identify inherently submissive individuals. Inherently submissive animals usually account for $20 \%$ of the population (Hayden-Hixson and Ferris, 1991). These animals were identified as individuals fleeing immediately to avoid an adult intruder placed in their cage and were eliminated from the study. Noninherently submissive animals initiated contact with the intruders through olfactory investigations. Afterward, noninherently submissive pups were weighed and separated into two groups (controls and subjugated). The groups were counterbalanced for body weight. Animals in the experimental group (subjugated) were placed daily in the home cage of an aggressive adult male for a $30 \mathrm{~min}$ period between P28 and P42. This postnatal period corresponds to puberty in golden hamsters (Vomachka and Greenwald, 1979). During these sessions, experimental animals were subjected to attacks, chase, and bites by the adults. The number of attacks observed during these sessions ranged between 5 and 35 over the $30 \mathrm{~min}$ period. These subjugation periods did not result in any visible wounds. Animals in the control group (controls) were placed daily in a clean cage for a 30 min period between P28 and P42. On P45 (young adults), all animals were weighted, tested for offensive aggression, and killed immediately afterward. All hamsters were kept under a reverse day light cycle (14/10 hr light/dark; lights on at 7 P.M.) and received food and water ad libitum.

Behavior. Offensive aggression was tested using a resident-intruder paradigm. An intruder was placed in the home cage of the subjects, and behaviors were recorded for a $10 \mathrm{~min}$ period by two independent observers. Most animals were videotaped for further verification of the recorded behaviors. Two types of tests were performed according to the size and age of the intruders. In the first case, the intruders were smaller and younger (70-80 gm, P25-P35) and had been themselves subjugated by aggressive adults during the day before testing. These animals displayed submissive behavior toward these adults and, therefore, were easy targets (representing nonthreatening stimuli) for the residents. In the other case, the intruders were of the same age and weight as the residents and had no experience of social stress during puberty. These animals had been selected as noninherently submissive around P28 and, therefore, were more daring targets (representing threatening stimuli) for the residents. The behaviors recorded during testing consisted of the latency to bite, numbers of bites, numbers of attacks, and total duration of contact time. The results were compared between groups using Student's $t$ tests (two-tailed, for parametric data) or Mann-Whitney tests (twotailed, for nonparametric data).

AVP levels. On P45, golden hamsters were killed by decapitation. Their brains were quickly taken out, frozen on dry ice, and kept at $-80^{\circ} \mathrm{C}$. Later, the brains were cut into $500-\mu \mathrm{m}$-thick sections with a cryostat. The sections were thaw-mounted on glass slides and kept frozen until microdissected. Microdissection consisted of a punch (diameter, $500 \mu \mathrm{m}$ ) taken from each half of the anterior hypothalamus, above the optic chiasma and optic tract (Ferris et al., 1989). The two punches were combined and assayed for AVP content as described previously (Ferris et al., 1989). The resulting levels were compared between groups as picograms per punch with Student's $t$ test (two-tailed). All sections were saved for later determination of the exact location of the punches. Data from punches located outside of the correct area were taken out of the study.

AVP immunocytochemistry. The distribution of AVP immunoreactivity (AVP-IR) was compared between subjugated $(n=5)$ and control $(n=5)$ hamsters. On P45, the hamsters were decapitated, and their brains were quickly taken out and fixed by immersion in $10 \%$ acrolein (Aldrich, Milwaukee, WI) in $0.1 \mathrm{M}$ potassium phosphate buffer (KPBS, $\mathrm{pH} 7.2$ ) for $6 \mathrm{hr}$. Later, the brains were kept overnight in $20 \%$ sucrose in KPBS. The brains were sliced at $50 \mu \mathrm{m}$ in a cryostat, and the sections were saved in $0.05 \mathrm{M}$ Tris-buffered saline, $\mathrm{pH}$ 7.6. Immunocytochemistry for AVP was performed on the sections as described previously (Delville et al., 1994; Ferris et al., 1995). Briefly, the sections were pretreated with
$1 \%$ sodium borohydrite (to eliminate residual aldehyde), followed by a preincubation in $20 \%$ normal goat serum containing $1 \%$ hydrogen peroxide and $0.3 \%$ Triton X-100 (to block nonspecific labeling and to eliminate endogenous peroxidase activity, respectively). The sections were then incubated in primary antiserum for AVP (rabbit anti-arginine vasopressin, 1:16,000; ICN ImmunoBiologicals, Lisle, IL), containing 2\% normal goat serum and $0.3 \%$ Triton $\mathrm{X}-100$ for $1 \mathrm{hr}$ at $37^{\circ} \mathrm{C}$. After washing in TBS, the sections were incubated in the secondary antibody (biotinylated goat anti-rabbit; Vector Laboratories, Burlingame, CA) followed by a tertiary incubation (Vectastain ABC Elite kit, Vector). Between incubations, the sections were washed in TBS. Finally, the sections were labeled with diaminobenzidine (DAB, $0.5 \mathrm{mg} / \mathrm{ml}$ ) and $0.05 \%$ hydrogen peroxide.

The density of AVP-IR fibers within the anterior hypothalamus was compared between the groups. The density of AVP-IR was quantified by gray level thresholding (Shipley et al., 1989; Bamshad et al., 1993) in digitized images using IMAGE software (version 1.56; National Institutes of Health, Bethesda, MD) and obtained from a video camera (TM-745; Pulnix America, distributed by Motion Analysis, Eugene, OR) mounted on a microscope. The images were imported on a MacIntosh computer with a frame grabber (LG-3; Scion, Walkersville, MD). The area selected for analysis was above the optic chiasma and optic tract and just ventrolateral to the nucleus circularis. This area contains a recognizable cluster of AVP-IR fibers (Ferris et al., 1989, 1997) (Fig. 1). The sections were observed with a $10 \times$ lens to maximize the capture of AVP-IR fibers within the area. The results were expressed as the area (square micrometers) covered by immunoreactive signal (in this case AVP-IR fibers) within the sample surface (a 250 - $\mu$ m-diameter circle). Four to 10 independent measurements were taken from several consecutive sections for each animal. These measures were averaged for each animal, and the averages were compared between groups (Student's $t$ test, two-tailed).

5-HT immunocytochemistry. Immunocytochemistry for 5-HT was performed on sections from animals (experimental, $n=5$; control, $n=4$ ) perfused intracardially with $0.9 \%$ saline containing $2 \%$ sodium nitrite followed by $4 \%$ paraformaldehyde in $0.1 \mathrm{M}$ PBS. Perfusions were performed on P45 in animals anesthetized with sodium pentobarbital (Nembutal, $35 \mathrm{mg} / \mathrm{kg}$; Abbott, North Chicago, IL), after an intracardiac injection of heparinized saline $(5000 \mathrm{U} / \mathrm{ml})$. After perfusion, the brains were taken out, post-fixed in 4\% paraformaldehyde for 30-60 min, and kept overnight at $4^{\circ} \mathrm{C}$ in $20 \%$ sucrose in $0.1 \mathrm{M}$ PBS. Brain sections were processed for immunocytochemistry to $5-\mathrm{HT}$ as explained above. After preincubation, the sections were incubated in the primary antibody (rabbit anti-5-HT, 1:4000; Eugene Tech International, Ramsey, NJ) at $4^{\circ} \mathrm{C}$ for at least $48 \mathrm{hr}$. Later, the sections were incubated in the secondary antibody (biotinylated goat anti-rabbit, Vector) and labeled with nickelconjugated DAB (Berghorn et al., 1994) after a tertiary incubation (Vectastain ABC Elite kit, Vector). This procedure resulted in a blue and black labeling of fibers and varicosities in the forebrain (Fig. 1). Omission of the primary antibody prevented any labeling.

The density of 5-HT IR varicosities was estimated within the ventral part of the lateral septum (at the level of rostral end of the anterior division of the bed nucleus of the stria terminalis) and the anterior hypothalamus (above the optic chiasma and optic tract and just ventrolateral to the nucleus circularis). Varicosities were counted from digitized images captured with a video camera mounted on a microscope (using a $100 \times$ objective) and imported on a computer with a frame grabber. The gray scale distribution of each image was standardized on the monitor, using the IMAGE software (Shipley et al., 1989). Varicosities were counted within standard circles ( $15 \mu \mathrm{m}$ diameter). Three to five samples were taken from each image to calculate an average number of varicosities per sample area in the image. Four to 10 consecutive sections were imaged for each area in each animal to calculate average numbers of varicosities per area. The individual averages were compared between the experimental and control groups with Student's $t$ test (two-tailed) for each area analyzed.

\section{RESULTS}

\section{Behavior}

Interestingly, the subjugated animals showed a 5\% increase in body weight at the end of the study (P45) compared with their nonsubjugated counterparts. Body weights averaged $127 \pm 12 \mathrm{gm}$ in subjugated animals versus $121 \pm 12 \mathrm{gm}$ in controls. This difference was statistically significant $\left(t_{(60)}=2.06 ; p<0.05\right)$. 

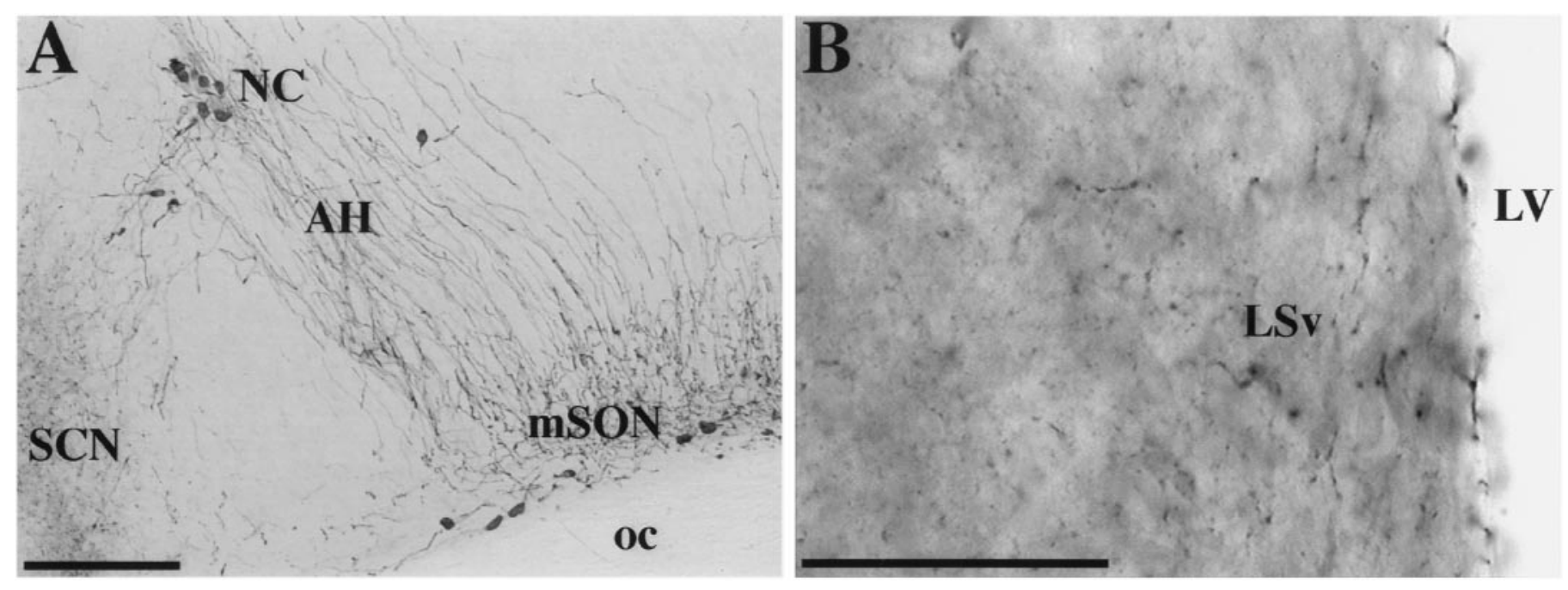

Figure 1. Photomicrographs showing AVP-IR $(A)$ within anterior hypothalamus $(A H)$ and 5-HT-IR $(B)$ within the ventral part of the lateral septum $(L S v)$ of golden hamsters. $L V$, Lateral ventricle; $m S O N$, medial division of the supraoptic nucleus; $N C$, nucleus circularis; $S C N$, suprachiasmatic nucleus; $o c$, optic chiasma. Scale bars: $A, 200 \mu \mathrm{m} ; B, 50 \mu \mathrm{m}$.
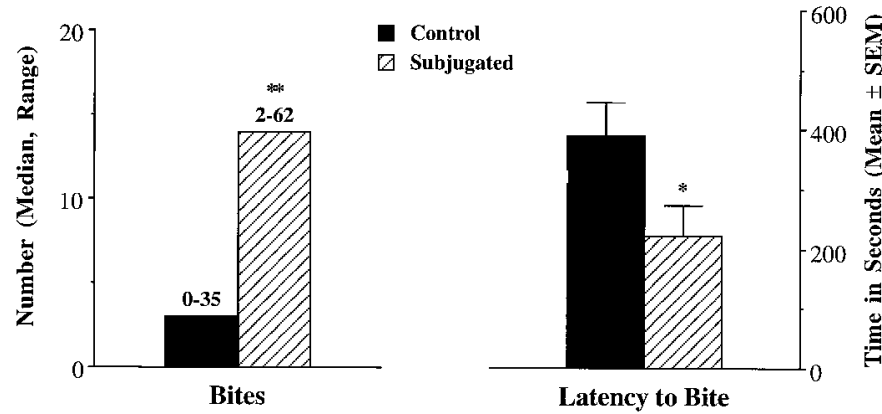

Figure 2. Aggressive behavior performed toward younger and smaller intruders. Experimental animals (Subjugated, $n=17$ ) were exposed daily to aggressive adult males from $\mathrm{P} 28$ to $\mathrm{P} 42$, whereas control hamsters $(n=$ 17) were placed in empty clean cages. The subjects (Control or Subjugated) were tested for a 10 min period on P45. * $p<0.05$, Student's $t$ test; ${ }^{* *} p<0.01$, Mann-Whitney test.

Offensive aggression was tested in experimental $(n=9)$ and control $(n=9)$ animals using smaller and younger intruders (70-80 gm, P25-P35). These intruders were 35-40\% lighter than the residents. During these tests, the intruders displayed submissive postures, often starting at the onset of the tests. In these conditions, subjugated animals were more likely than the controls to be aggressive toward the intruders. Subjugated animals were faster (latency to bite, $221.9 \pm 150.8$ vs $389.2 \pm 169.9 \mathrm{sec} ; t_{(16)}=$ $2.21 ; p<0.05)$ and more likely than the controls to bite the intruders (number of bites, 14 bites, ranging from 2 to 62, vs 2 bites, ranging from 0 to $\left.22 ; U=13 ; U^{\prime}=68 ; p<0.05\right)$. The numbers of attacks and contact times were not recorded during these testing procedures. Similar testing was performed with additional animals $(n=8+8)$. However, their intruders had no previous experience of subjugation. During these tests, some intruders were not particularly submissive. These tests led to similar differences between controls and subjugated hamsters. The data from the second set were pooled with the first set (Fig. 2 ). The differences between groups remained statistically significant (latency to bite, $t_{(32)}=2.18 ; p<0.05$; bites, $U=118 ; U^{\prime}=$ 411; $p<0.01)$.

Other animals $(n=12+12)$ were tested with intruders of
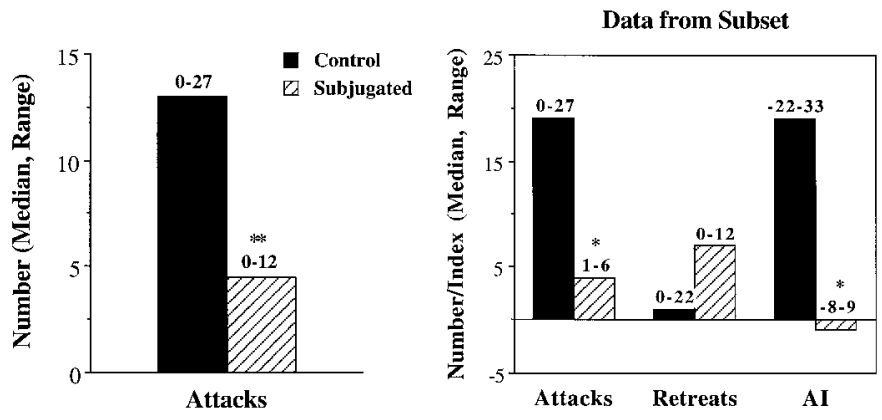

Figure 3. Aggressive behavior performed toward intruders of equal size and age. Experimental animals (Subjugated, $n=12$ ) were exposed daily to aggressive adult males from $\mathrm{P} 28$ to $\mathrm{P} 42$, whereas control hamsters $(n=$ $12)$ were placed in empty clean cages. The subjects were tested for a 10 min period on P45. Data from a subset of animals $(n=7+7)$ was used to compare retreats and calculate an aggression index $(A I$; bites plus attacks minus retreats). ${ }^{*} p<0.05 ;{ }^{* *} p<0.01$, Mann-Whitney tests.

equal age and size (Fig. 3). During these tests, few animals (controls, 6 of 12; subjugated, 3 of 12) bit their intruders. In control animals, the median number of bites reached only 0.5 , ranging from zero to six, whereas in subjugated animals the median number of bites was zero, ranging from zero to six. However, most animals attacked the intruders at least once. Interestingly, subjugated animals were less likely to attack their intruders than the controls. The differences were statistically significant $\left(U=26.5 ; U^{\prime}=117.5 ; p<0.01\right)$. Furthermore, some residents, particularly subjugated animals, retreated from the intruders, and displayed submissive postures. Retreats were later compared between groups in one subset of animals $(n=7+7)$. In this subset, five of seven subjugated animals retreated from the intruder more than once (compared with two of seven controls). The difference between groups was not statistically significant for this subset $\left(U=16 ; U^{\prime}=33 ; p>0.1\right)$, attributable to the presence of one particularly hyperactive control animal that was fleeing from the intruder. However, these numbers allowed the calculation of an aggression index (attacks plus bites minus retreats) (Ferris et al., 1989). These indices were significantly higher in controls than in subjugated animals $\left(U=7.5 ; U^{\prime}=41.5 ; p<\right.$ 


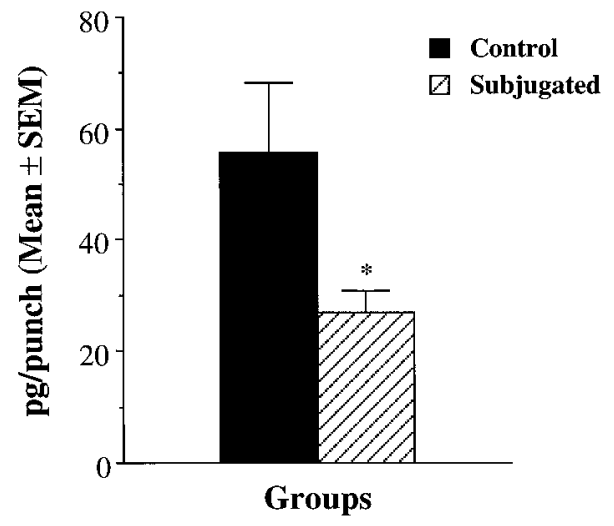

Figure 4. Comparison of hypothalamic AVP contents within the anterior hypothalamus of subjugated and control hamsters. Subjugated animals were exposed to aggressive adults during peripubescence. The results are expressed as picograms of AVP per punch taken within the anterior hypothalamus. ${ }^{*} p<0.05$, Student's $t$ test.

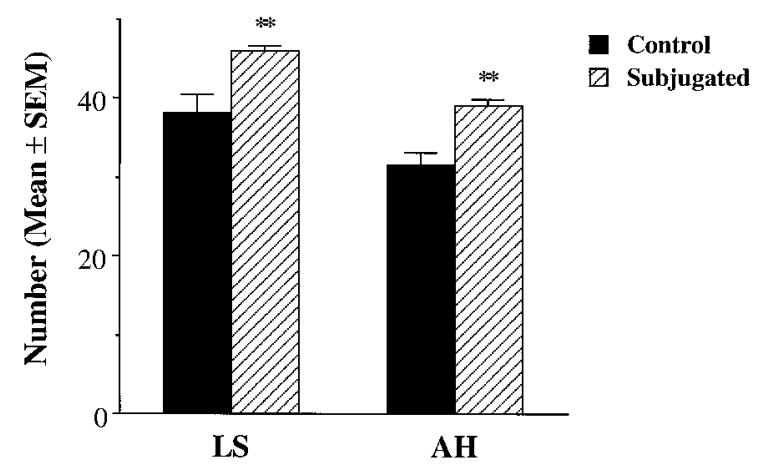

Figure 5. Comparison of the density of 5-HT-IR varicosities within the anterior hypothalamus $(A H)$ and lateral septum $(L S)$ of subjugated $(n=$ $5)$ versus control $(n=4)$ hamsters. Varicosities were counted within standard surfaces $(15-\mu \mathrm{m}$-diameter circles) placed over digitized images. ${ }^{* *} p<0.01$, Student's $t$ test.

0.05). Finally, contact times were compared for all animals. All animals spent equal periods with their intruders, averaging 400 sec in both groups $\left(t_{(22)}=1.46 ; p>0.1\right)$.

\section{AVP levels}

Vasopressin levels in the anterior hypothalamus were compared between subjugated $(n=13)$ and control $(n=14)$ animals. The levels were $50 \%$ lower in subjugated animals than in controls (Fig. 4 ), and the differences were statistically significant $\left(t_{(25)}=2.15\right.$; $p<0.05)$.

\section{Immunocytochemistry}

Vasopressin-IR was observed in subjugated and control animals. The mean area covered by AVP-IR fibers within the anterior hypothalamus was slightly reduced in subjugated animals compared with controls $\left(4068 \pm 1352\right.$ vs $\left.4736 \pm 1335 \mu \mathrm{m}^{2}\right)$. However, these differences were not statistically significant $\left(t_{(8)}=0.79 ; p>\right.$ $0.1)$.

The numbers of 5-HT-IR varicosities within the lateral septum and anterior hypothalamus were counted in all animals (Fig. 5). More 5-HT-IR varicosities were counted in the lateral septum than in the anterior hypothalamus in control and subjugated animals. However, in both areas, social subjugation was associated with a $\sim 20 \%$ increase in the number of 5-HT-IR varicosities. These differences were statistically significant for both areas (lat- eral septum, $t_{(7)}=3.53 ; p<0.01$; anterior hypothalamus, $t_{(7)}=$ 4.33; $p<0.01)$.

\section{DISCUSSION}

The present results show that social subjugation during puberty results in a context-dependent alteration of aggressive behavior. During testing, animals in the control groups reacted to the intruders rather similarly regardless of size. In both tests, control hamsters were not particularly aggressive to the intruders, biting them only a few times. In contrast, the behavior of subjugated animals differed strongly between tests. In the presence of a small intruder (nonthreatening stimulus), subjugated animals were particularly aggressive and were more likely and faster to bite the intruders than the controls. However, the behavior was different in the presence of an intruder of equal size ("threatening stimulus"). In this case, subjugated animals were not particularly aggressive and tended to retreat from the intruders. This resulted in a near absence of bites, low number of attacks, and low aggression index. Compared with controls, subjugated animals were even less likely to engage the intruders and had lower aggression indices. These results confirm the importance of context during agonistic behavior testing.

When pairing hamsters for the study of agonistic behavior, it is particularly important to consider the weight of the animals. Larger animals tend to win fights against smaller opponents (Payne and Swanson, 1970). In the present experiments, the body weights of the experimental and control groups were carefully counterbalanced at the beginning of the study. Furthermore, during testing with intruders of equal age and size, the residents and intruders were carefully matched by body weights. Hence, at the end of the study, differences in body weights between groups should not have been a factor during testing with an intruder of equal age and size. Moreover, although there was a small difference in body weights between groups, it is also unlikely that this factor played a critical role in the behavioral results from the tests in the presence of a smaller and younger intruder. The difference in body weights between groups was limited to $5 \%$, whereas the difference in body weights between residents and intruders was much greater.

The present results may also be relevant to studies on children and adolescents, because this second age group is the target of a high rate of abuse (Paperny and Deisher, 1983). Aggressive behavior of previously abused children is not always predictable (Martin and Elmer, 1992). In some cases, physical abuse has been associated with withdrawal and depression in children (Gutierres and Reich, 1981). Conversely, experiencing abuse during childhood has also been identified as an important risk factor for parental abuse of children (Silver et al., 1969; Kaufman and Ziegler, 1987). Greater attention to context could lead to a better understanding of the behavior performed by these children.

The behavioral alterations resulting from social subjugation were correlated with changes in the 5-HT and AVP systems. Vasopressin content was $50 \%$ lower in the anterior hypothalamus of subjugated animals compared with controls. However, this decrease was not associated with a decrease in the density of AVP fibers within the anterior hypothalamus. Although not statistically significant, the density of AVP-IR within the anterior hypothalamus was lower in subjugated animals. It is possible that a larger selection of animals would have lowered the variability within groups and would have shown statistically significant differences. Nevertheless, a reduction in AVP levels combined with unaltered AVP innervation suggests that AVP neurons produce 
and release less AVP within the anterior hypothalamus, although remaining capable of doing so. These results are consistent with the behavioral observations. Because AVP facilitates aggression, subjugated animals are still capable of releasing the neuropeptide within the anterior hypothalamus.

One explanation for the behavioral observations reported in these results involves AVP release within the anterior hypothalamus. The conditions in which AVP is released within the anterior hypothalamus in subjugated animals may be more limited than in their nonsubjugated controls. Subjugated animals may be less likely to release AVP within the anterior hypothalamus in the presence of a stressful or threatening stimulus, such as an animal of equal size. However, in the presence of nonthreatening stimuli such as a smaller intruder, subjugated animals remain capable of releasing AVP to facilitate aggression. It is also possible that the reduced levels of AVP produced in the hypothalamus of these animals may affect AVP receptors. Lower levels of AVP within the hypothalamus may be associated with increased responsiveness to the neuropeptide and upregulation of the receptors. This possibility would help explaining the behavior of these animals in the presence of a nonthreatening stimulus.

In contrast to the observations made with AVP, 5-HT innervation of the anterior hypothalamus was denser in subjugated animals than in controls. This increased density suggests an enhanced capacity to release 5-HT. This increased density of 5-HT terminals is not limited to the anterior hypothalamus. Social subjugation was also associated with increased number of 5-HT-IR varicosities within the lateral septum, another area involved in the regulation of agonistic behaviors by AVP (Irvin et al., 1990; Koolhaas et al., 1991), connected directly within the anterior hypothalamus (Ferris et al., 1990). In this area, defeat is associated with increased cellular activity, as evidenced by increased c-fos mRNA labeling (Kollack-Walker et al., 1997). This indicates that the effects of social subjugation may affect the 5-HT system within several elements of the neural network regulating agonistic behaviors.

Because 5-HT inhibits aggression, these results are consistent with the observation that subjugated animals were less aggressive toward intruders of equal size. Furthermore, stressful stimulation has been associated with an activation of 5-HT release and/or turnover in the brain (De Souza and Van Loon, 1986; Adell et al., 1988; Blanchard et al., 1993). Perhaps the serotonin system of subjugated animals may be more responsive to stressful or threatening stimuli, resulting in a greater release of 5-HT in the presence of an intruder of equal size. This effect would, then, result in an inhibition of aggressive behavior and an enhanced frequency of submissive or avoidance behaviors. However, why would these same animals be very aggressive in the presence of a small intruder? It could be argued that the daily stress of subjugation throughout adolescence promotes an exaggerated synthesis and release of 5-HT. Consequently, there may be a downregulation of postsynaptic 5-HT receptors. This downregulation might blunt the 5-HT response under environmental conditions that normally withdraw 5-HT activity, such as the presence of a nonthreatening, smaller intruder that can be easily defeated. This possibility is consistent with previous observations made in rats in response to social stress. Indeed, subordinates have been found less responsive to 5-HT agonists than dominants (Raleigh et al., 1984). Furthermore, social stress has been associated with decreased 5- $\mathrm{HT}_{1 \mathrm{~A}}$ receptor binding (McKrittick et al., 1995) and a deactivation of $5-\mathrm{HT}_{1 \mathrm{~B}}$ receptors (Bolanos-Jimenez et al., 1995) in the brain.
The present experiments tested the effects of chronic stress resulting from social subjugation on subsequent aggressive behavior and raise the possibility that puberty may be a vulnerable developmental window. However, it is possible that such effects are not limited to this developmental period. It is possible that experiments testing the effect of stress earlier in development could show effects on the development on the AVP and 5-HT systems in correlation with context-dependent changes in agonistic behavior. Furthermore, it is also possible that exposure to social stress during adulthood would also affect both behavior and neurobiology. Indeed, previous data showed an interaction between dominance and the presence of testosterone on subsequent display of flank-marking behavior and the distribution of AVP-IR within the anterior hypothalamus in male golden hamsters (Ferris et al., 1989).

Nevertheless, chronic exposure to social stress has been associated with reduced activity of the hypothalamo-pituitary-gonadal (HPG) axis in adult animals (Collu et al., 1979; Raab et al., 1986; Taylor et al., 1987; Huhman et al., 1991; Blanchard et al., 1993). Such effect could have more profound consequences during puberty. A delay in the maturation of the HPG axis could, in turn, affect aggressive behavior and the AVP and 5-HT systems. Indeed, testosterone has been involved in the regulation of agonistic behaviors, such as scent marking and aggression toward intruders (Payne, 1974; Johnston, 1981). Moreover, testosterone can also affect AVP and 5-HT neurons as well as their receptors. In golden hamsters, up to $25 \%$ of AVP neurons in the hypothalamus and up to $50 \%$ of 5-HT neurons in the dorsal raphe nuclei contain androgen receptors (Y. Delville, unpublished data). Furthermore, AVP receptors within the anterior hypothalamus and ventrolateral hypothalamus are also testosterone-dependent (Delville and Ferris, 1995; Johnson et al., 1995). Finally, the preponderance of androgen receptors within 5-HT neurons suggest that testosterone may also affect the density of 5-HT synapses. The possibility that the effects of chronic social stress are at least partly mediated by a delay in the maturation of the HPG axis could be tested in further experiments.

\section{REFERENCES}

Adell A, Garcia-Marquez C, Armario A, Gelpi E (1988) Chronic stress increases serotonin and noradrenaline in rat brain and sensitize their responses to a further acute stress. J Neurochem 50:1678-1681.

Bamshad M, Novak MA, De Vries GJ (1993) Sex and species differences in the vasopressin innervation of sexually naive and parental prairie voles (Microtus ochrogaster) and meadow voles (Microtus pennsylvanicus). J Neuroendocrinol 5:247-256.

Berghorn KA, Bonnett JH, Hoffman GE (1994) cFos immunoreactivity is enhanced with biotin amplification. J Histochem Cytochem 42:1635-1642.

Blanchard DC, Sakai RR, McEwen BS, Blanchard RJ (1993) Subordination stress: behavioral and neuroendocrine correlates. Behav Brain Res 58:113-121.

Blanchard DC, Spencer RL, Weiss SM, Blanchard RJ, McEwen BS, Sakai RR (1995) Visible burrow system as a model of chronic social stress: behavioral and neuroendocrine correlates. Psychoneuroendocrinology 20:117-134.

Bolanos-Jimenez F, Manhaes de Castro RM, Cloez-Tarayani I, Monneret V, Drieu K, Fillion G (1995) Effects of stress on the functional properties of pre- and postsynaptic $5-\mathrm{HT}_{1 \mathrm{~B}}$ receptors in the rat brain. Eur J Pharmacol 294:531-540.

Coccaro EF (1996) Neurotransmitter correlates of impulsive aggression in humans. In: Understanding aggressive behavior in children, Vol 794 (Ferris CF, Grisso T, eds), pp 82-89. New York: New York Academy of Sciences.

Collu R, Tache Y, Ducharme JR (1979) Hormonal modifications induced by chronic stress in rats. J Steroid Biochem 11:989-1000.

Delville Y, Ferris CF (1995) Sexual differences in vasopressin receptor 
binding within the ventrolateral hypothalamus in golden hamsters. Brain Res 681:91-96.

Delville Y, Mansour KM, Yules B, Ferris CF (1994) Postnatal development of the vasopressinergic system in golden hamsters. Dev Brain Res 81:230-239.

Delville Y, Mansour KM, Ferris CF (1995) Serotonin blocks vasopressin-facilitated offensive aggression: interactions within the ventrolateral hypothalamus of golden hamsters. Physiol Behav 59:813-816.

Delville Y, Mansour KM, Ferris CF (1996) Testosterone facilitates aggression by modulating vasopressin receptors in the hypothalamus. Physiol Behav 60:25-29.

De Souza EB, Van Loon GR (1986) Brain serotonin and catecholamine responses to repeated stress in rats. Brain Res 367:77-86.

Ferris CF (1996) Serotonin diminishes aggression by suppressing the activity of the vasopressin system. In: Understanding aggressive behavior in children, Vol 794 (Ferris CF, Grisso T, eds), pp 98-103. New York: New York Academy of Sciences.

Ferris CF, Potegal M (1988) Vasopressin receptor blockade in the anterior hypothalamus suppresses aggression in hamsters. Physiol Behav 44:235-239.

Ferris CF, Axelson JF, Martin AM, Roberge LF (1989) Vasopressin immunoreactivity in the anterior hypothalamus is altered during the establishment of dominant/subordinate relationships between hamsters. Neuroscience 29:675-683.

Ferris CF, Gold L, De Vries GJ, Potegal M (1990) Evidence for a functional relationship between the lateral septum and the hypothalamus in the control of flank marking behavior in golden hamsters. J Comp Neurol 293:476-485.

Ferris CF, Delville Y, Miller MA, Dorsa DM, De Vries GJ (1995) Distribution of small vasopressinergic neurons in golden hamsters. J Comp Neurol 360:589-598.

Ferris CF, Melloni RH, Koppel G, Perry KW, Fuller RW, Delville Y (1997) Vasopressin/serotonin interactions in the anterior hypothalamus control aggressive behavior in golden hamsters. J Neurosci 17:4331-4340.

Gutierres S, Reich JA (1981) A developmental perspective on runaway behavior: its relationship to child abuse. Child Welfare 60:89-94.

Haller J, Makara GB, Barna I, Kovacs K, Nagy J, Vecsernyes M (1996) Compression of the pituitary stalk elicits chronic increases in CSF vasopressin, oxytocin as well as in social investigation and aggressiveness. J Neuroendocrinol 8:361-365.

Hayden-Hixson DM, Ferris CF (1991) Cortisol exerts site-, context- and dose-dependent effects on agonistic responding in hamsters. J Neuroendocrinol 3:613-622.

Huhman KL, Moore TO, Ferris CF, Moughey EH, Meyerhoff JL (1991) Acute and repeated exposure to social conflict in male golden hamsters: increases in plasma POMC-peptides and cortisol and decreases in plasma testosterone. Horm Behav 25:206-216.

Irvin RW, Szot P, Dorsa DM, Potegal M, Ferris CF (1990) Vasopressin in the septal area of the golden hamster controls scent marking and grooming. Physiol Behav 48:693-699.

Johnson AE, Barberis C, Albers HE (1995) Castration reduces vasopressin receptor binding in the hamster hypothalamus. Brain Res 674:153-158

Johnston RE (1981) Testosterone dependence of scent marking by male hamsters (Mesocricetus auratus). Behav Neural Biol 31:96-99.

Joppa MA, Rowe RK, Meisel RL (1997) Effects of serotonin 1A or 1B receptor agonists on social aggression in male and female Syrian hamsters. Pharmacol Biochem Behav 58:349-353.

Kaufman J, Ziegler E (1987) Do abused children become abusive parents? Am J Orthopsychiatry 57:186-192.

Kollack-Walker S, Watson SJ, Akil H (1997) Social stress in hamsters: defeat activates specific neurocircuits within the brain. J Neurosci 17:8842-8855.

Koolhaas JM, Van den Brink THC, Roozendaal B, Boorsma F (1990)
Medial amygdala and aggressive behavior; interaction between testosterone and vasopressin. Aggr Behav 16:223-229.

Koolhaas JM, Moor E, Hiemstra Y, Bohus B (1991) The testosteronedependent vasopressinergic neurons in the medial amygdala and lateral septum: involvement in social behaviour of male rats. In: Vasopressin (Jard S, Jamison R, eds), pp 213-219. Paris: INSERM/John Libbey Eurotext.

Kraemer GW, Clarke AS (1996) Social attachment, brain function, and aggression. In: Understanding aggressive behavior in children, Vol 794 (Ferris CF, Grisso T, eds), pp 121-135. New York: New York Academy of Sciences.

Martin JA, Elmer E (1992) Battered children grown up: A follow-up study of individuals severely maltreated as children. Child Abuse Negl 16:75-87.

McKrittick CR, Blanchard DC, Blanchard RJ, McEwen BS, Sakai RR (1995) Serotonin receptor binding in a colony model of chronic social stress. Biol Psychiatry 37:383-393.

Olivier B, Mos J (1990) Serenics, serotonin and aggression. In: Current and future trends in anticonvulsant, anxiety, and stroke therapy (Meldrum BS, Williams M, eds), pp 203-230. New York: Wiley.

Paperny DM, Deisher RW (1983) Maltreatment of adolescents: the relationship to a predisposition toward violent behavior and delinquency. Adolescence 18:499-506.

Payne AP (1974) A comparison of the effects of androstenedione, dihydrotestosterone and testosterone propionate on aggression in the castrated male golden hamster. Physiol Behav 13:21-26.

Payne AP, Swanson HH (1970) Agonistic behaviour between pairs of hamsters of the same and opposite sex in a neutral observation area. Behaviour 36:259-269.

Potegal M, Huhman K, Moore T, Meyerhoff J (1993) Conditioned defeat in the Syrian golden hamster (Mesocricetus auratus). Behav Neural Biol 60:93-102.

Raab A, Dantzer R, Michaud B, Marmede P, Taghzouti K, Simon H, Le Moal M (1986) Behavioral, physiological and immunological consequences of social status and aggression in chronically coexisting resident-intruder dyads of male rats. Physiol Behav 36:223-228.

Raleigh MJ, Brammer GL, McGuire MT, Yuwiler A (1984) Dominant status facilitates the behavioral effects of serotoninergic agonists. Brain Res 348:274-282.

Sachser N (1993) The ability to arrange with conspecifics depends on social experiences around puberty. Physiol Behav 53:539-544.

Shipley MT, Luna J, McLean JH (1989) Processing and analysis of neuroanatomical images. In: Neuroanatomical tract tracing methods II (Heimer L, Zaborsky L, eds), pp 331-390. New York: Plenum.

Sijbesma H, Schipper J, De Kloet ER (1990) The anti-aggressive drug eltoprazine preferentially binds to $5-\mathrm{HT}_{1 \mathrm{~A}}$ and $5-\mathrm{HT}_{1 \mathrm{~B}}$ receptor subtypes in rat brain: sensitivity to guanine nucleotides. Eur J Pharmacol 187:209-223.

Sijbesma H, Schipper J, De Kloet ER, Mos J, van Aken H, Olivier B (1991) Postsynaptic 5- $\mathrm{HT}_{1}$ receptors and offensive aggression in rats: a combined behavioral and autoradiographic study with eltoprazine. Pharmacol Biochem Behav 38:447-458.

Silver LB, Dublin CC, Lourie RS (1969) Does violence breed violence? Contribution from a study of the child abuse syndrome. Am J Psychiatry 126:404-407.

Taylor GT, Weiss J, Rupich R (1987) Male rat behavior, endocrinology and reproductive physiology in a mixed-sex, socially stressful colony. Physiol Behav 39:429-433.

Vomachka AJ, Greenwald GS (1979) The development of gonadotropin and steroid hormone patterns in male and female hamsters from birth to puberty. Endocrinology 105:960-966.

Winslow JT, Hastings N, Carter CS, Harbough CR, Insel TR (1993) A role for central vasopressin in pair bonding in monogamous prairie voles. Nature 365:545-548. 